\title{
Effect of dietary linoleic acid on the progression of chronic renal failure in rats
}

S.M.P. Gregório², C.C.S. Lemos $^{1}$,

M.L. Caldas ${ }^{2}$ and R. Bregman ${ }^{1}$
1Divisão de Nefrologia, Universidade Estadual do Rio de Janeiro, Rio de Janeiro, RJ, Brasil

Divisão de Patologia, Universidade Federal Fluminense, Niterói, RJ, Brasil

\section{Correspondence}

R. Bregman

Rua Soares Cabral, 71/401

22240-070 Rio de Janeiro, RJ Brasil

Fax: +55-21-587-6250

E-mail: bregmanr@uol.com.br

Received August 27, 2001

Accepted March 6, 2002

\section{Abstract}

The role of linoleic acid in chronic renal failure (CRF) is controversial. In the present study 21 male Wistar rats submitted to $5 / 6$ renal mass reduction $(\mathrm{R})$ and 16 normal controls $(\mathrm{C})$ were fed a supplement $(\mathrm{S})$ or normal (N) linoleic acid diet for 60 days starting 10 days after CRF. As expected, serum creatinine, cholesterol and triglycerides (mean \pm SEM) were higher in the CRF groups compared to the $\mathrm{C}$ groups $(\mathrm{P}<0.05)$. The RS group presented lower cholesterol $(84 \pm 4$ vs $126 \pm$ $13 \mathrm{mg} \%$ ) and triglyceride ( $88 \pm 9$ vs $132 \pm 19 \mathrm{mg} \%$ ) levels compared to the RN group. Proteinuria and kidney weight did not differ between CRF groups. Glomerular area increased $78 \%$ in RS and $100 \%$ in RN compared to control rats. Glomerular sclerosis index tended to be lower in RS (27\%) compared to RN (38\%), tubulointerstitial damage was similar between $\mathrm{CRF}$ groups $(\mathrm{RS}=1.91 \pm 0.2$ and $\mathrm{RN}=2.14 \pm$ 0.3 ), and mesangial fractional volume increased to the same extent in both CRF groups. The data suggest that a linoleic acid-enriched diet did not protect against the progression of CRF after 60 days.

\section{Introduction}

In the 1980 's, the diet started to be considered the factor that would solve almost all problems related to the progression of chronic renal failure (CRF) (1). The protein diet has been extensively studied, together with some other dietary components. Lipids and precursors of some autacoids like prostaglandins and leukotrienes have also been implicated in the progression of CRF (2-4). Dietary prostaglandin precursors are different in different parts of the world. Linoleic acid, common in the western diet, and eicosapentanoic acid, common in the diet of inhabitants of the far north, are examples of this

\section{Key words}

- Chronic kidney failure

- Diet

- Glomeruli

- Linoleic acid difference. Many studies have compared these two sources of prostaglandins (those from dienoic series with those of trienoic series) but with inconclusive results (5-7). Studies using different experimental models such as a 5/6 reduction of renal mass, lupus nephritis, and immunologic glomerulonephritis have suggested that increases in vasodilatory prostaglandins could retard the progression of CRF (8-10).

Following experimental reduction in renal mass, the glomerular and urinary excretion of prostaglandins and thromboxane $\mathrm{A}_{2}$ increases several-fold $(11,12)$. There is evidence that these substances play a role in the progression of CRF $(13,14)$. Prostaglandins 
and thromboxanes are cyclic derivatives of polyunsaturated fatty acids (PUFAs) (1517). Linoleic acid is an essential fatty acid ingested at the rate of approximately $10 \mathrm{~g}$ per day, and is the most abundant fatty acid in western diets. It is present in many vegetable oils and is the precursor of arachidonic acid. Some beneficial effects of PUFAs, especially linoleic acid, are related to the reduction of blood pressure $(18,19)$, platelet aggregability and blood viscosity $(2,5)$. Subtotally nephrectomized rats fed a low linoleic acid diet had progressive deterioration of renal function. By contrast, those fed the high linoleic acid diet had better preservation of renal function with less proteinuria and glomerular sclerosis $(20,21)$, and also an increase in the renal content of arachidonic acid (22). Other investigators have shown that rats with CRF fed a linoleic acid-enriched diet had an increase in proteinuria and glomerular sclerosis index (GSI), and also a worsened progression of CRF (23).

The role of linoleic acid in the diet of animals with CRF has not been established regarding the progression of $\mathrm{CRF}$, despite the studies published in the last years $(1,9,13,22)$. Thus, the objective of the present investigation was to study the effects of a high and low linoleic acid content in the diet on the progression of CRF.

\section{Material and Methods}

Male Wistar rats weighing 200 to $250 \mathrm{~g}$ at the beginning of the study were used. Animals were divided into two groups: controls (C) and animals submitted to 5/6 reduction (R) of total renal mass. Reduction of renal mass was performed by partial left nephrectomy, with an abdominal incision under ether anesthesia. The renal artery was isolated and two or three branches were ligated. Right nephrectomy was then performed immediately through a lumbar incision. This procedure was performed on day 0 , and the animals were maintained on a regular diet until the 10th day after surgery, when they started to receive the experimental diets. Control animals also started to receive the experimental diets at the same time as the CRF groups.

\section{Diets}

Each group was divided into two groups fed the experimental diet containing linoleic acid as $1.5 \%$ (normal, $\mathrm{N}$ ) or $21 \%$ (supplement, S) of the total caloric intake for 61 days. Throughout the study, the animals were pair-fed ( $\mathrm{CN} v s \mathrm{CS}$ and $\mathrm{RN} v s \mathrm{RS}$ ). At the beginning of the study, animals were paired according to body weight and food consumption. Body weight and food consumption were determined daily throughout the study. Diets were elaborated in the Experimental Laboratory of the Faculty of Nutrition, Federal Fluminense University, Rio de Janeiro, RJ, Brazil, using an adaptation of the model of Tobian et al. (24). The diet consisted of $80 \%$ of standard Purina ${ }^{\circledR}$ rodent chow (Campinas, SP, Brazil), which was ground to a powder, and $20 \%$ soy oil or butter, with water added to form a paste. The diet was homogenized with an industrial mixer (Hobart), transformed into pellets and dried in an oven (Fabber Primar). After drying, the diets were identified and stored under refrigeration. All ingredients were weighed on a digital electronic scale.

The diet called "N", in which butter was the main source of lipids, contained approximately $0.67 \mathrm{~g}$ linoleic acid/100 g chow, which corresponded to $1.5 \%$ of the total energy, i.e., a normal linoleic acid content. The "S" diet, which contained soy oil, had approximately $9.60 \mathrm{~g}$ of linoleic acid/100 g chow, which corresponded to $21 \%$ of the total energy, corresponding to a linoleic acid-rich diet. Both diets offered about $400 \mathrm{kcal} / 100 \mathrm{~g}$ and $19 \%$ protein. The estimated centesimal chemistry composition (Table 1) of the experimental diets followed established criteria (25). 
A sample of each diet was analyzed for linoleic acid content by the Brazilian Company of Agriculture and Stock Raising Research (EMBRAPA). The result showed that the "S" diet had nine times more linoleic acid than the "N" diet. The basic composition of the standard chow from Labina/ Purina ${ }^{\circledR}$, according to the manufacturer, contains corn, wheat bran, soy bran, meat meal, raw rice meal, calcium carbonate, bicalcium phosphate, and salt.

\section{Groups}

The following groups were studied: control group fed the diet with normal linoleic acid content ( $\mathrm{CN}, \mathrm{N}=9), \mathrm{CRF}$ group fed the diet with normal linoleic acid content $(\mathrm{RN}$, $\mathrm{N}=10$ ), control group fed the linoleic acidrich $\operatorname{diet}(\mathrm{CS}, \mathrm{N}=7)$, and $\mathrm{CRF}$ group fed the linoleic acid-rich diet ( $R S, N=11)$. On days 21,41 and 61 after starting the specific diets, 24 -h proteinuria was determined. Urine was collected in metabolic cages, where the animals were kept only with water ad libitum. Blood was collected at the end of the study to measure serum creatinine, cholesterol and triglycerides.

\section{Morphology}

At the end of the study, the kidneys were perfused with $1.25 \%$ glutaraldehyde in sodium phosphate buffer, $\mathrm{pH}$ 7.4. Kidney fragments were fixed, and 3-4- $\mu \mathrm{m}$ sections were stained with periodic acid-Schiff. Glomerular area was determined after measuring the glomerular diameter with a caliper mounted on the eyepiece. The reported glomerular area is the mean of 25 measurements. The GSI was determined by measuring the frequency of sclerosis in 100 glomeruli from each animal as described by Raij et al. (26), and the result is reported as the median. A score of 0 to $4+$ was assigned to each glomerulus according to the extent of sclerosis: normal glomerulus, 0 ; up to $25 \%$ involve- ment, $1+$; up to $50 \%$ involvement, $2+$; up to $75 \%$ involvement, $3+$; more than $75 \%$ involvement, $4+$. The GSI score for each animal was the sum of individual glomerular scores multiplied by the percent of glomeruli with the same score. Tubulointerstitial damage was evaluated as described by Shih et al. (27). Briefly, cortical involvement was examined and graded according to a 0 to 4 scale $(0=$ normal, $0.5=$ small focal areas of cellular infiltration and tubular damage, $1=$ involvement of less than $10 \%$ of the cortex, $2=$ involvement up to $25 \%$ of the cortex, $3=$ involvement up to 50 to $75 \%$ of the cortex, and $4=$ involvement greater than $75 \%$ ). Additionally, mesangial fractional volume (Vv) was measured in ten glomeruli from each animal using the M42 test-system grid; Vv was estimated by counting the number of points falling on mesangium (pMes), including its matrix and cellular components, using $\mathrm{Vv}=$ pMes $\times 100 / 42$ (28).

\section{Analytical procedures}

Serum creatinine, cholesterol and triglycerides were determined with an autoanalyzer in the Central Laboratory of the Pedro Ernesto Hospital. Proteinuria was determined using the sulfosalicylic acid method.

\section{Statistical analysis}

Data are reported as means \pm SEM, and medians were compared by analysis of variance. The difference between groups was determined by the Duncan test. The Mann-

Table 1. Estimated centesimal chemistry of the diets.

\begin{tabular}{|c|c|c|c|c|c|c|}
\hline & \multirow[t]{2}{*}{ Proteins } & \multirow[t]{2}{*}{ Glucides } & \multirow[t]{2}{*}{ Lipids } & \multicolumn{2}{|c|}{ Energy } & \multirow{2}{*}{$\frac{\text { Linoleic acid }}{\% / \text { energy }}$} \\
\hline & & & & kcal & $\mathrm{g} / 100$ & \\
\hline$N$ & 19.78 & 35.87 & 19.1 & 394.5 & 0.67 & 1.53 \\
\hline S & 19.78 & 38.35 & 20.0 & 412.5 & 9.60 & 21.0 \\
\hline
\end{tabular}

$\mathrm{N}, \mathrm{S}=$ normal and supplemented linoleic acid diets, respectively. 
Figure 1. Effect of linoleic acid dietary supplement on serum cholesterol (Chol) and triglycerides (Tri) 61 days after renal mass reduction. For group abbreviations, see legend to Table 2 . $+\mathrm{P}<0.05$ compared to $\mathrm{CS}$; $* \mathrm{P}<0.05$ compared to $\mathrm{CN}$ (Duncan test).
Whitney test was used to compare GSI data. The differences were considered to be statistically significant if $\mathrm{P} \leq 0.05$.

\section{Results}

Body weights after surgery on the day the animals began the specific diet were: $\mathrm{CS}=$

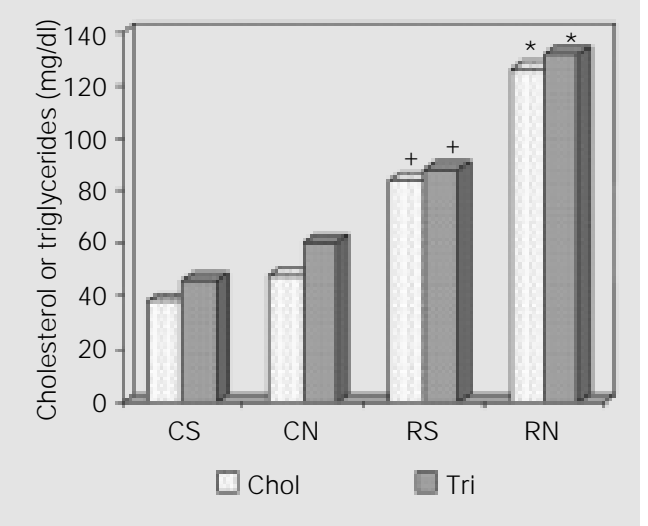

Figure 2. Effect of linoleic acid dietary supplement on proteinuria (PTN) 21, 41 and 61 days after renal mass reduction. For group abbreviations see legend to Table 2. $+\mathrm{P}<0.05$ compared to $\mathrm{CS} ; * \mathrm{P}<0.05$ compared to $\mathrm{CN}$ (Duncan test).

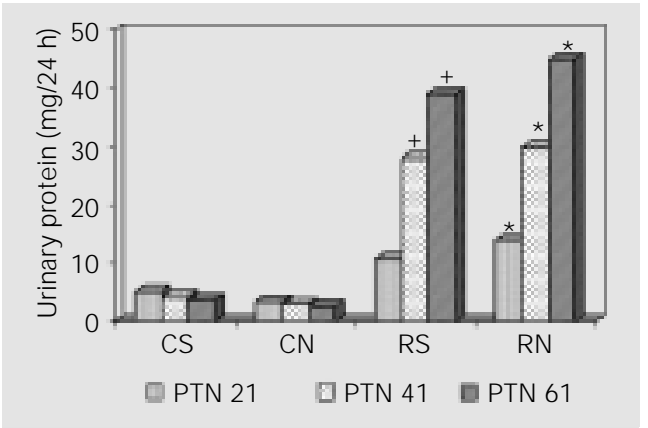

Table 2. Effect of linoleic acid dietary supplement on kidney morphology after mass reduction.

\begin{tabular}{lcccc}
\hline & $\mathrm{CS}$ & $\mathrm{CN}$ & $\mathrm{RS}$ & $\mathrm{RN}$ \\
\cline { 2 - 5 } & $\mathrm{N}=7$ & $\mathrm{~N}=7$ & $\mathrm{~N}=6$ & $\mathrm{~N}=7$ \\
\hline $\mathrm{GA}\left(\mu \mathrm{m}^{2} \times 10^{3}\right)$ & $11 \pm 0.8$ & $9.6 \pm 0.4$ & $19 \pm 1.1^{+}$ & $20 \pm 0.4^{*}$ \\
$\mathrm{GSI}$ & 0 & 0 & $36(3-112)$ & $22(21-103)$ \\
TID & 0 & 0 & $1.9 \pm 0.2$ & $2.1 \pm 0.3$ \\
$\mathrm{VV}(\%)$ & $62 \pm 2.6$ & $64 \pm 1.7$ & $62 \pm 0.7$ & $63 \pm 2.1$ \\
\hline
\end{tabular}

$\mathrm{GA}=$ glomerular area, GSI = glomerular sclerosis index, TID = tubulointerstitial damage, $\mathrm{VV}=$ mesangial fractional volume, $\mathrm{C}=$ control, $\mathrm{R}=5 / 6$ renal mass reduction, $\mathrm{S}=$ linoleic acid-rich diet, $\mathrm{N}=$ normal linoleic acid diet. Data are reported as means $\pm \mathrm{SEM}$ or as medians. ${ }^{+} \mathrm{P}<0.02$ compared to $\mathrm{CS}$; $* \mathrm{P}<0.02$ compared to $\mathrm{CN}$ (Duncan test for all parameters and Mann-Whitney for GSI).
$323 \pm 8, \mathrm{CN}=317 \pm 6, \mathrm{RS}=258 \pm 12$, and $\mathrm{RN}=231 \pm 11 \mathrm{~g}$, and at the end of the study were $\mathrm{CS}=387 \pm 10, \mathrm{CN}=367 \pm 7, \mathrm{RS}=317$ \pm 15 , and $\mathrm{RN}=282 \pm 14 \mathrm{~g}$. $\mathrm{C}$ groups were different from the respective $\mathrm{R}$ groups $(\mathrm{P}<0.001)$. Mean serum creatinine values were: $\mathrm{CS}=0.65 \pm 0.06, \mathrm{CN}=0.69 \pm 0.03$, $\mathrm{RS}=1.44 \pm 0.12$, and $\mathrm{RN}=1.80 \pm 0.42$ $\mathrm{mg} \%$. The CRF groups presented higher creatinine values $(\mathrm{P}<0.05)$, and $\mathrm{RN}$ tended to be higher than RS. Cholesterol values were higher in the CRF groups compared to their respective controls after 61 days (Figure 1). The RN group showed higher serum lipid levels compared to RS $(\mathrm{P}<0.05)$. Values for proteinuria were higher in the $\mathrm{CRF}$ groups after 21, 41 and 61 days $(\mathrm{P}<0.05)$ except for RS compared to CS after 21 days (Figure 2). Values for kidney weight: $\mathrm{CS}=$ $1.41 \pm 0.09, \mathrm{CN}=1.19 \pm 0.06, \mathrm{RS}=1.44 \pm$ 0.08 , and $\mathrm{RN}=1.13 \pm 0.06 \mathrm{~g}$, were not statistically different among groups. Values for glomerular area, GSI, and tubulointerstitial damage were higher in CRF groups compared to the respective controls, but were not significantly different among them. Mesangial fractional volume was not different among the groups studied (Table 2).

\section{Discussion}

The diets were isocaloric and all groups showed the same percentage of increase in body weight, suggesting that the diet was adequate.

Animals fed a normal linoleic acid diet showed a worse lipid profile when compared to those fed a high linoleic acid diet. Disturbance of lipid metabolism, a characteristic of CRF $(29,30)$, has been associated with the development of glomerular sclerosis, and consequently with the progression of CRF $(31,32)$. The mechanisms whereby lipids contribute to renal injury are incompletely understood. The PUFAs of the $n-6$ and n-3 series have beneficial effects on plasma lipids. Those of the $n-6$ series are 
more effective in reducing cholesterol (23) whereas those of the n-3 series exert their main effect on triglycerides and their effect on lipoproteins has been questioned (33). It has also been suggested that PUFAs improve renal lesions not by reducing the serum levels of lipoproteins, but by modifying lipoprotein composition, their deposition within the glomeruli or the cholesterol or ester composition in the tissues (20,34-36).

A marked increase in proteinuria was observed in both CRF groups, suggesting that glomerular selectivity was compromised to the same extent in both groups. Some studies have shown that dietary supplementation with PUFAs reduces proteinuria and prevents functional deterioration in immune complex glomerulonephritis, and in genetic systemic lupus erythematosus $(2,3,8)$. Dietary supplementation by linoleic acid prevented functional deterioration after subtotal nephrectomy in rats (37). Heifets et al. (22) showed that a linoleic acid-enriched diet fed to female rats with CRF led to an increase in glomerular filtration rate when compared with rats fed a low linoleic acid diet. Additionally, they showed better levels of arterial pressure and proteinuria. It has been suggested that PUFAs of the $n-6$ series may reduce the deterioration of renal function and the glomerular sclerosis of rats with CRF (20,21,30). Conversely, Brown et al. (38) found that in dogs with CRF, supplementation with omega 6 PUFA enhanced renal injury, and supplementation with omega 3 was renoprotective. In a study evaluating partially nephrectomized rats fed a high linoleic acid diet (21), protection of renal function was demonstrated, but both groups developed proteinuria. However, proteinuria occurred later and was significantly less severe in rats fed the high linoleic acid diet. Serum cholesterol and triglycerides were not different between groups. Protection of the renal architecture was also demonstrated in CRF rats fed the high linoleic acid diet. The authors suggested that evolution of CRF could be prevented by increasing the linoleic acid content of the diet, and showed that this protection was associated with increased cortical production of PGE2. These data show that there is no consensus about this issue and they should be interpreted carefully, firstly because they are not homogenous and secondly because different models of progressive renal disease were used as well as different strains of rats.

Animals submitted to $75 \%$ reduction of total renal mass showed kidney weights that did not differ from control. These data suggest the occurrence of hypertrophy of the residual kidney (1), and show that this process was independent of the dietary lipid content. The glomerular area was larger in the CRF groups, increasing $78 \%$ in the RS group and $100 \%$ in the RN group. GSI and tubulointerstitial damage increased to the same extent in the CRF groups, while Vv did not change, suggesting that diet did not affect these parameters. These results were expected since proteinuria, that is considered to be the main mediator of mesangial expansion and tubulointerstitial damage (39), was similar between CRF groups.

Sometimes the extent of glomerular lesion is correlated with serum cholesterol (40). Endogenous hyperlipidemia in obese Zucker rats is well correlated with the development of albuminuria and glomerular lesion. When the animals are treated with lipid-lowering agents, albuminuria decreases, and glomerular lesions (40) as well as mesangial matrix expansion are reduced (33). Thus, in some forms of glomerular lesion, serum lipid reduction is associated with the reduction of the structural lesions of the kidney.

In the present study we found that animals with CRF fed a linoleic acid-enriched diet had a better serum lipid profile; however, other indicators of renal function and architecture were not different from controls. These data suggest that lowering serum lipids is not the main mechanism for 
protecting renal function in this model.

Questions related to the source of lipids

of the diet, playing a role in the progression
ofCRF, remain unanswered, and longer studies will be necessary to answer them.

\section{References}

1. Klahr S, Schreiner G \& Ichikawa I (1988). The progression of renal disease. New England J ournal of Medicine, 318: 16571666.

2. Barcelli UO \& Pollak VE (1985). Is there a role for polyunsaturated fatty acids in the prevention of renal disease and renal failure? Nephron, 41: 209-212.

3. Lianos EA (1989). Eicosanoids and the modulation of glomerular immune injury. Kidney International, 35: 985-992.

4. Lebbel M \& Grose J H (1986). Abnormal renal prostaglandin production during evolution of chronic nephropathy. American J ournal of Nephrology, 6: 96-100.

5. von Schacky C, Fischer $\mathrm{S} \&$ Weber PC (1985). Long-term effects of dietary marine-3 fatty acids upon plasma and cellular lipids, platelet function, and eicosanoid formation in humans. J ournal of Clinical Investigation, 76: 1626-1631.

6. Scharschmidt LA, Lianos E \& Dunn MJ (1983). Arachidonate metabolites and the control of glomerular function. Federation Proceedings, 42: 3058-3063.

7. Kromhout B, Bosschieter EB \& Coulander CDL (1985). The inverse relation between fish consumption and 20-year mortality from coronary heart disease. New England J ournal of Medicine, 312: 1205-1209.

8. Barcelli UO \& Pollak VE (1986). Prostaglandins and the progressive renal insufficiency. In: Mitch WE, Brenner BM \& Stein $\mathrm{JH}$ (Editors), The Progressive Nature of Renal Disease, Contemporary Issues in Nephrology. Churchill Livingstone, New York, NY, USA.

9. Cappelli P, Di Liberato $L \&$ Albertazzi $A$ (1998). Role of dyslipidemia in the progression of chronic renal disease. Renal Failure, 20: 391-397.

10. Hirschberg $R$, von Herrath D, Klaus $H$, Höfer W, Schuster C, Rottka H \& Schaefer K (1984). Effect of diets containing varying concentrations of essential fatty acids and triglycerides on renal function in uremic rats and NZB/NZW F1 mice. Nephron, 38: 233-237.

11. Blum $M$, Bauminger S, Algueti A, Kisch E, Ayalon D \& Aviram A (1981). Urinary prostaglandin-E2 in chronic renal disease. Clinical Nephrology, 15: 87-89.
12. Purkerson $M L$, J oist J H, Yates J , Valdes A, Morrison A \& Klahr S (1985). Inhibition of tromboxane synthesis ameliorates the progressive kidney disease of rats with subtotal renal ablation. Proceedings of the National Academy of Sciences, USA, 82: 193-197.

13. Klahr S \& Harris K (1989). Role of dietary eicosanoids on the progression of renal disease. Kidney International, 36 (Suppl 27): 27-31.

14. Izumi $Y$, Weiner TW, Franco-Saenz $R \&$ Mulrow PJ (1986). Effects of dietary linoleic acid on blood pressure and renal function in subtotally nephrectomized rats. Proceedings of the Society for Experimental Biology and Medicine, 183: 193-198.

15. Schlondorff D \& Ardaillou R (1986). Prostaglandins and other arachidonic acid metabolites in the kidney. Kidney International, 29: 108-119.

16. StorkJ E, Rahman MA \& Dunn MJ (1986). Eicosanoids in experimental and human renal disease. American J ournal of Medicine, 80 (1A): 34-45.

17. Stahl RA, Kudelka $S$, Paravicini $M \&$ Schollmeyer P (1986). Prostaglandin and thromboxane formation in glomeruli from rats with reduced renal mass. Nephron, 42: 252-257.

18. Ito $Y$, Barcelli U, Yamashita W, Weiss $M$, Deddens J \& Pollak VE (1987). A low protein-high linoleate diet increases glomerular PGE2 and protects renal function in rats with reduced renal mass. Prostaglandins, Leukotrienes and Medicine, 28: 277284.

19. Horrobin DF, Manku MS \& Huang YS (1984). Effects of essential fatty acids on prostaglandin biosynthesis. Biomedica Biochimica Acta, 43: S114-S120.

20. Barcelli UO, Miyata J, Ito Y, Gallon L, Laskarzewski P, Weiss M, Hitzemann R \& Pollak VE (1986). Beneficial effects of polyunsaturated fatty acids in partially nephrectomized rats. Prostaglandins, 32: 211-219.

21. Barcelli UO (1991). Effect of dietary prostaglandin precursors on the progression of renal disease in animals. Kidney International, 31: 57S-64S.

22. Heifets $M$, Morrissey J , Purkerson ML,
Morrison AR \& Klahr S (1987). Effect of dietary lipids on renal function in rats with subtotal nephrectomy. Kidney International, 32: 335-341.

23. Klahr S, Buerkert J \& Purkerson ML (1983). Role of dietary factors in the progression of chronic renal disease. Kidney International, 24: 579-587.

24. Tobian L, Ganguli M, J ohnson MA \& Iwai J (1982). Influence of renal prostaglandins and dietary linoleate on hypertension in Dahl S rats. Hypertension, 4 (Suppl II): II.149-II.153.

25. Report of the American Institute of Nutrition Ad Hoc Committee on Standards for Nutritional Studies (1978). Nutrient Requirements of Laboratory Animals. National Academy of Sciences, Washington, DC, USA.

26. Raij L, Azar S \& Keane WF (1984). Mesangial immune injury, hypertension and progressive glomerular damage in Dahl rats. Kidney International, 26: 137-143.

27. Shih W, Hines WH \& Neilson EG (1988). Effects of cyclosporin A on the development of immune-mediated interstitial nephritis. Kidney International, 33: 11131118.

28. Weibel ER, Kistler GS \& Scherle WF (1966). Practical stereological methods for morphometric cytology. Journal of Cell Biology, 30: 23-38.

29. Attman PO \& Gustafson A (1989). Abnormalities of lipid metabolism. In: Giovannetti S (Editor), Nutritional Treatment of Chronic Renal Failure. Kluwer Academic Publishers, Boston, MA, USA.

30. Barcelli UO \& Pollak VE (1989). Manipulation of alimentary lipids for the treatment of chronic renal failure. In: Giovannetti S (Editor), Nutritional Treatment of Chronic Renal Failure. Kluwer Academic Publishers, Boston, MA, USA.

31. Kasiske BL, O'Donnell MP, Schmitz PG, Kim Y \& Keane WF (1990). Renal injury of diet-induced hypercholesterolemia in rats. Kidney International, 37: 880-891.

32. Kasiske BL, O'Donnell MP, Margot PC \& Keane WF (1989). Effects of reduced renal mass on tissue lipids and renal injury in hyperlipidemic rats. Kidney International, 35: 40-47.

33. Harris WS, Connor WE \& McMurry MP 
(1983). The comparative reductions of the plasma lipids and lipoproteins by dietary polyunsaturated fats: Salmon oil versus vegetable oils. Metabolism, 32: 179-184.

34. Attman PO \& Alaupovic P (1991). Lipid abnormalities in chronic renal insufficiency. Kidney International, 39 (Suppl 31): 16-23.

35. Maschio G, Oldrizzi L, Rugiu C, De Biase V \& Loschiavo C (1991). Effect of dietary manipulation on the lipid abnormalities in patients with chronic renal failure. Kidney International, 39: S70-S72.
36. Keane WF (2000). The role of lipids in renal disease: Future challenges. Kidney International, 57 (Suppl 75): S27-S31.

37. Ingram AJ , Parbtani A, Clark WF, Spanner E, Huff MW, Philbrick DJ \& Holub BJ (1995). Effects of flaxseed and flax oil diets in a rat $5 / 6$ renal ablation model. American J ournal of Kidney Diseases, 25: 320-329.

38. Brown SA, Brown CA, Crowell WA, Barsanti J Á, Allen T, Cowell C \& Finco DR (1998). Beneficial effects of chronic administration of dietary omega-3 polyun- saturated fatty acids in dogs with renal insufficiency. J ournal of Laboratory and Clinical Medicine, 131: 447-455.

39. Benigni A, Zoja C \& Remuzzi G (1995). The renal toxicity of sustained glomerular protein traffic. Laboratory Investigation, 73: 461-468.

40. Keane WF, Kasiske BL, O'Donnell MP \& Schmitz PG (1989). Therapeutic implications of lipid lowering agents in the progression of renal disease. American J ournal of Medicine, $87: 21 \mathrm{~N}-24 \mathrm{~N}$. 